\title{
O IMPACTO DA EXTENSÃO NA FORMAÇÃO DISCENTE, A EXPERIÊNCIA COMO PRÁTICA FORMATIVA: UM ESTUDO NO CONTEXTO DE UM INSTITUTO FEDERAL NO RIO GRANDE DO SUL
}

\author{
THE IMPACT OF OUTREACH ACTIVITIES ON \\ UNDERGRADUATE EDUCATION, EXPERIENCE AS \\ FORMATIVE PRACTICE: A STUDY IN THE CONTEXT OF \\ A FEDERAL INSTITUTE IN RIO GRANDE DO SUL
}

\section{RESUMO:}

Laiane Frescura Flores* ORCID: https://orcid.org/0000-0001-7600-4698

Débora Teixeira de Mello** ORCID: https://orcid.org/0000-0002-3017-9000

O Instituto Federal Farroupilha tem como missão promover cursos de educação profissional, científica e tecnológica, pública e gratuita, por meio do ensino, pesquisa e extensão, com foco na formação integral do cidadão e no desenvolvimento sustentável. O presente estudo analisou quais as contribuições/impacto da extensão para a formação acadêmica e profissional dos discentes participantes destas açõ̂es no Campus de São Borja, pertencente ao Instituto Federal Farroupilha. A metodologia utilizada caracterizou-se como uma pesquisa qualitativa e quantitativa, sob estudo de caso. Os sujeitos de pesquisa foram alunos participantes de ações de extensão e servidores que atuaram como coordenadores. Os resultados apontaram que estas ações são relevantes e significativas para os alunos, pois auxiliam de forma efetiva tanto na formação acadêmica, profissional, como também na formação humana e cidadã dos envolvidos. Pode-se observar que a interação e o convívio com o público das comunidades e Instituições atendidas proporcionou aos alunos a construção e o aprimoramento de habilidades, crescimento pessoal e profissional, incorporação de novas práticas, trocas de experiências, visão crítica acerca da realidade e das desigualdades, trabalho em equipe, possibilidades de participação em eventos e de produção científica. Concluiu-se que as ações de extensão proporcionam formação e um currículo diferenciado, qualificando o conhecimento científico e popular, promovendo a transformação social.

Palavras chave: Ações de extensão; Prática formativa; Institutos federais.

\begin{abstract}
:
The mission of the Farroupilha Federal Institute is to promote free, public, professional, scientific and technological education through teaching, research and outreach activities, focusing on integral citizen education and sustainable development. This study aims to analyze the contributions/impact of outreach activities on the academic and professional formation of students involved in outreach projects in the aforementioned campus. It was a qualitative quantitative research in the form of a case study. The research participants were students involved in outreach actions and institute staff who acted as coordinators. The results pointed out that these actions are relevant and significant for the students, as they have a positive impact on the academic, professional, and on the human and citizen formation of the paticipants. It was observed that the interaction and socialization with the communities and institutions attended, provided students the construction and improvement of skills, personal and professional growth, incorporation of new practices, exchange of experiences and critical view of reality and inequalities. Other results include learning to work in teams, and oppotunities to participate in events and increase scientific production. It was concluded that outreach activities provide training and a differentiated curriculum, which in turn improve scientific and popular knowledge and promote social transformation.
\end{abstract}

Keywords: Outreach actions; Formative practice; Federal institutes. 


\section{Introdução}

A prática histórica da extensão tem origem na concepção de universidade detentora do saber, único, verdadeiro, iluminado, que, por um lado, deveria ser transferido à população e, por outro, deveria ser colocado para assistir à população com o provimento de algum serviço. Esses modelos conceituais e institucionais receberam críticas e formulações de alternativas para o surgimento de uma extensão universitária mais engajada, dialogada e próxima da população excluída. As novas proposições pressupõem uma ação processual e contínua, não pontual, em que o conhecimento científico interaja com os demais saberes da população, em um diálogo permanente, visando à produção de conhecimentos e à apropriação para a resolução de problemas concretos das pessoas e de suas organizações (SOUSÁ, 2000).

Conforme Severino (2007), a extensão universitária deve ser entendida como o processo que articula o ensino e a pesquisa, enquanto interage conjuntamente, criando um vínculo fecundante entre a Universidade e a sociedade, no sentido de levar esta contribuição do conhecimento para sua transformação. Ao mesmo tempo em que a extensão, enquanto ligada ao ensino, enriquece o processo pedagógico ao envolver docentes, alunos e comunidade num movimento comum de aprendizagem, enriquece o processo político ao se relacionar com a pesquisa, dando alcance social à produção do conhecimento.

Potencialmente, a extensão constitui um espaço de vivências, de construção da autonomia, de autodesenvolvimento, de autoaprendizagem e de processos individuais mediados pelas inter-relações com o outro e com o contexto. É um espaço-tempo privilegiado para construir teias entre realidade, vida, conhecimento e saber acadêmico, cujo processo-produto é a formação do estudante universitário. Segundo essa perspectiva, as experiências propiciadas nos diferentes lócus de ação da extensão universitária irão contribuir decisivamente para a formação dos estudantes, em diferentes aspectos: pessoal, social, comunitário e profissional (SIVERES, 2013, p. 216).

Nessa perspectiva, a presente pesquisa buscou investigar/analisar quais as contribuições para a formação acadêmica e profissional do aluno participante de ações de extensão do Instituto Federal Farroupilha - Campus São Borja.

Considerando os documentos norteadores do FORPROEXT (Fórum de PróReitores de Extensão, da Rede Federal de Educação Científica e Tecnológica), o Instituto Federal Farroupilha busca oferecer aos educandos oportunidades de vivenciar experiências na sua área de formação acadêmica e profissional e o acesso a atividades que contribuam para a sua formação cultural e ética, desenvolvendo o seu senso crítico, a cidadania e a responsabilidade social.

Os Institutos Federais possuem fortes vínculos identitários com as políticas de extensão, uma vez que sua legislação e demais documentos regulatórios elencam a extensão como missão institucional e atividade essencial nas comunidades em que estão inseridos, atuando como propulsores do desenvolvimento local e regional.

\section{Metodologia}

A presente pesquisa caracteriza-se como qualitativa e quantitativa, bem como, classifica-se como bibliográfica, documental e estudo de caso. Para Gil (2012, p. 57), o estudo de caso é caracterizado pelo estudo profundo e exaustivo de um ou de poucos objetos, de maneira a permitir o seu conhecimento amplo e detalhado, tarefa quase impossível mediante os outros tipos de delineamentos considerados. 
Os sujeitos da pesquisa foram os alunos participantes das ações de extensão realizadas nos anos de 2017 e 2018, do Instituto Federal Farroupilha (IFFar) - Campus São Borja. Também houve a participação de 5 coordenadores de ações de extensão, tendo sido selecionados coordenadores das seguintes áreas: meio ambiente, direitos humanos e justiça, tecnologia e produção, cultura e educação.

Como forma de selecionar quais coordenadores seriam entrevistados, foi considerada a variável maior número de vezes que o servidor atuou como coordenador ou colaborador em projetos de extensão em ambos os anos. Os participantes da pesquisa foram os seguintes:

Quadro 1 - Sujeitos da pesquisa.

\begin{tabular}{|l|c|c|}
\hline \multicolumn{1}{|c|}{ Participantes da pesquisa } & Técnica utilizada & Participantes (amostra) \\
\hline Alunos participantes & Questionário online & 30 \\
\hline Coordenadores de ações de extensão & Entrevista semiestruturada & 05 \\
\hline
\end{tabular}

Fonte: Elaborado pela autora (2019).

Os coordenadores entrevistados foram identificados como: Coordenador 1, 2, 3, 4 e 5. Os alunos participantes da pesquisa foram identificados da seguinte forma:

Quadro 2 - Identificação dos alunos.

\begin{tabular}{|l|c|c|c|}
\hline \multicolumn{1}{|c|}{ Cursos dos alunos } & Abreviação & Respondentes & Denivações \\
\hline Ensino médio integrado & EMI & 06 & EMI1 à EMI6 \\
\hline Técnicos Subsequentes & SUB & 03 & SUB1 à SUB3 \\
\hline Cursos superiores & SUP & 17 & SUP1 à SUP17 \\
\hline Sem matrícula ativa (alunos egressos) & SMA & 04 & SMA1 à SMA4 \\
\hline
\end{tabular}

Fonte: Elaborado pela autora (2019).

Para o tratamento dos dados, utilizou-se a técnica de análise de conteúdo. Bardin (2009) configura a análise de conteúdo como um conjunto de técnicas de análise das comunicações que utiliza procedimentos sistemáticos e objetivos de descrição do conteúdo das mensagens. São fases da análise de conteúdo: 1. Pré-análise; 2. Exploração do material; 3. Tratamento dos resultados através da inferência e da interpretação.

A análise dos dados foi sistematizada de acordo com as diretrizes da Política Nacional de Extensão: interação dialógica, interdisciplinaridade e interprofissionalidade, indissociabilidade do ensino-pesquisa-extensão, impacto na formação do estudante e impacto e transformação social.

\section{Os Institutos Federais e a relação com a extensão}

Segundo a Lei $\mathrm{n}^{\circ} 11.892 / 08$, os institutos federais são definidos como: instituições de educação superior, básica e profíssional, pluricurricular e multicampi, especializada na oferta de educação profissional e tecnológica nas diferentes modalidades de ensino. Equiparados às universidades, os institutos são instituições acreditadoras e certificadoras de competências profissionais, além de detentores de autonomia universitária.

Neste sentido, Pereira (2009) salienta que o papel que está previsto para os institutos federais de Educação, Ciência e Tecnologia é o de garantir a perenidade das ações que visem incorporar, antes de tudo, setores sociais que historicamente foram alijados dos processos de 
desenvolvimento e modernização do Brasil, o que legitima e justifica a importância de sua natureza pública e afirma uma Educação Profissional e Tecnológica como instrumento realmente vigoroso na construção e resgate da cidadania e transformação social.

A relação entre sociedade e universidade, no que tange mais especificamente à extensão, vai além da compreensão tradicional de disseminação de conhecimento, prestação de serviço e difusão cultural, mas aponta para uma participação efetiva da comunidade na própria atuação da universidade, nos conhecimentos produzidos e em um consequente confronto com a realidade. Dentro desses balizamentos, a produção do conhecimento via extensão se faria na troca dos saberes sistematizado, acadêmico e popular, tendo como consequência a democratização do conhecimento, a participação efetiva da comunidade na atuação da universidade e uma produção resultante do confronto com a realidade (SILVA, 1997).

O fortalecimento destas inter-relações entre institutos federais/comunidade busca o enfrentamento das diversas situações de desigualdades, exclusão e vulnerabilidade social no local onde estão inseridos. Pela oferta de cursos, serviços, eventos, projetos, palestras e projetos sociais, os institutos federais não só geram e difundem conhecimentos e saberes, como exercem sua reponsabilidade social, comprometidos com a melhoria da qualidade de vida dos cidadãos, ofertando possibilidades de capacitação e qualificação.

Pode-se dizer que, sem a extensão, as universidades estarão desconectadas das comunidades em que estão inseridas, além de estarem alijadas de instrumentos e condições capazes de propiciar, aos novos profissionais, uma formação integral consolidada (SCHEIDEMANTEL, 2004).

Como forma de fomentar ações neste sentido, o Ministério da Educação instituiu, em 2008, o Programa de Extensão Universitária (ProExt). Seu objetivo, desde o princípio, além de destinar recursos aos projetos de extensão das instituições de ensino superior, foi regulamentar e aplicar os mecanismos de avaliação desenvolvidos pelo FORPROEX para análise da situação extensionista do Brasil. No ano de 2012, foi publicada a Política Nacional de Extensão. Esta importante política tem por objetivo promover a consolidação da Extensão, delineando princípios e diretrizes, monitoramento, avaliação e agendas estratégicas para a extensão. No entanto, no ano de 2016, o MEC extinguiu esta importante e única política de financiamento da extensão, deixando de lançar editais anuais e fomentar propostas de extensão. Neste sentido, as Universidades e Institutos Federais estão utilizando unicamente recursos orçamentários internos para cumprir com sua missão institucional de garantir a oferta de ações de extensão à sociedade.

O novo Plano Nacional de Educação 2014-2024, em vigência, traz como inovação a curricularização da extensão, em sua meta 12.7, em que busca assegurar que, no mínimo, $10 \%$ do total de créditos curriculares exigidos para a graduação seja cumprido pelos acadêmicos em programas e projetos de extensão, prioritariamente, em áreas de grande pertinência social (Lei 13.005/2014).

A curricularização da extensão, para que se cumpra esses $10 \%$ de crédito, é um grande desafio para as universidades, pois se faz necessária a sensibilização dos docentes e coordenadores de curso para as devidas adequações, uma vez que deixa de ser um componente eletivo para tornar-se item obrigatório na grade curricular. Requer, também, revisão dos projetos pedagógicos dos cursos para que as atividades de extensão estejam contempladas no currículo. Além da tarefa complexa de revisar/alterar todos os currículos, há ainda fatores dificultadores acerca da compreensão do papel da extensão na formação discente e, principalmente, como colocá-la em prática.

Nesse sentido, a extensão busca atender as demandas locais e regionais, em articulação com as políticas públicas, com os movimentos sociais e com o setor produtivo, no intuito de ofertar capacitação, qualificação e acesso a cursos de formação continuada aos atores sociais, como forma de promoção do desenvolvimento local e regional. 


\section{As ações de Extensão: a experiência como prática formativa}

O número total de sujeitos de pesquisa respondentes do questionário totalizou 30 estudantes, dos quais $86,7 \%$ (26 estudantes) que participaram de ações de extensão são do sexo feminino e apenas 13,3\% (4 estudantes) são do sexo masculino. Estes dados demostraram o protagonismo feminino na realização das ações de extensão, já que as mulheres representam maioria na efetivação e envolvimento com este tipo de ação.

Em relação à faixa etária dos estudantes participantes, a maioria tinha idade entre 15 a 20 anos, totalizando 43,3\% dos respondentes (13 estudantes). Logo após está a faixa etária de 21 a 25 anos, com 33,3\% (10 estudantes). Nesse sentido, constatou-se que a maior parte dos estudantes que participaram das ações são jovens que estão cursando o ensino médio integrado e/ou estão iniciando seus cursos superiores de graduação.

Quanto ao curso que o estudante estava matriculado quando desenvolveu/ participou da ação de extensão, 56,7\% (17 estudantes) estava vinculado aos cursos superiores de graduação. Logo a seguir, 20\% (6 estudantes) estavam matriculados nos cursos técnicos integrados ao ensino médio. Conforme observa-se no gráfico a seguir, $13,3 \%$ (4 estudantes) são alunos egressos, pois não possuem mais matrícula ativa com a Instituição.

Gráfico 1 - Curso em que o participante está/estava matriculado.
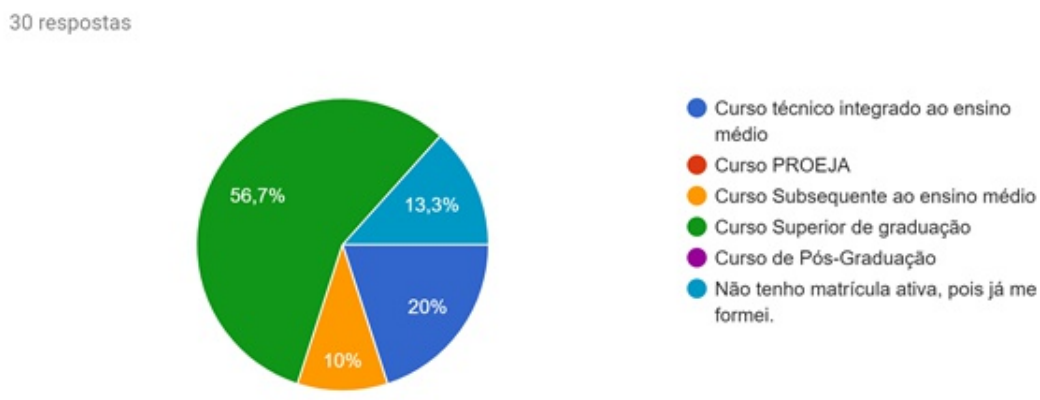

Fonte: Elaborado pela autora (2019).

Quanto ao ano em que o participante foi bolsista de extensão, observa-se que a maioria, 53,3\% (16 estudantes), atuou em ações de extensão tanto nos anos de 2017 quanto 2018, enfatizando, assim, a vontade própria do estudante de continuar participando deste tipo de ação, ano após ano, porque criou um vínculo com a Instituição e/ou comunidade em que realizou as ações de extensão e quer dar continuidade às ações propostas no ano anterior.

No ano de 2017, 23.3\% dos participantes (7) mencionaram ter participado das ações de extensão somente neste ano, bem como o mesmo percentual de $23.3 \%$ se repete no ano de 2018.

\section{Interação dialógica}

A extensão universitária, de acordo com o artigo 207 da Constituição de 1988, é uma ação indissociável ao ensino e à pesquisa. Essa prática acadêmica pode ser uma forma de aproximação para promover um diálogo com outros setores da sociedade, viabilizando uma produção de conhecimentos de forma colaborativa. 
Nesse sentido, a Coordenadora 3 faz uma explanação sobre a relevância da interação entre a Instituição e a comunidade, como forma de auxiliar no desenvolvimento local e regional, bem como para a formação do aluno:

\begin{abstract}
A instituição tem isso como prerrogativa, né, da tríade de ensino-pesquisaextensão. E aí como que não vai devolver nada? Porque a ideia da instituição, pelo que eu entendo e pelo que eu já acompanhei da história, é justamente modificar a região, mas não só no sentido de formação, mas de poder devolver para a comunidade as coisas que são feitas aqui para não ficar algo feito só para si. ão é somente no sentido de dar qualificação para as pessoas, mas também de poder retribuir para a comunidade de uma forma mais imediata. porque o aluno que entra aqui, leva 2, 3, 4 anos dependendo do curso, pra sair daqui e entrar no mercado de trabalho. Mas os projetos de extensão são mais diretos: traz, vai apresentando e já vai trazendo benefícios ao longo do curso mesmo. Além de, tipo, o aluno que participa disso, ele percebe que ele é além do profissional que ele vai se formar, ele percebe o poder que ele tem e percebe a relevância dessas ações (Coordenadora 3 ).
\end{abstract}

Para Larrosa (2002), a experiência é o que nos passa, o que nos acontece, o que nos toca. Não o que se passa, não o que acontece, ou o que toca. A cada dia se passam muitas coisas, porém, ao mesmo tempo, quase nada nos acontece. Dir-se-ia que tudo o que se passa está organizado para que nada nos aconteça. Quanto à relevância destas interações de trocas de conhecimentos e vivências, seguem os seguintes relatos:

\begin{abstract}
Para mim superou todas as minhas expectativas, o projeto que participei foi de Preparações Básicas em Cozinhas, realizado em um CRAS da cidade, o que mais me surpreendeu foi o conhecimento que essas mulheres tinham, conhecimento passado de geração em geração. Posso dizer que aprendi mais que ensinei, foi uma troca muito rica. Tem muitas técnicas também que só com a experiência você adquire e que eu enquanto estudante ainda não tinha (Aluno SUP04).
\end{abstract}

o ano de 2017 fui bolsista do PIBID e em 2018 participei de projetos de extensão: monitoria nas escolas estaduais do município e projeto de formação continuada, foi de grande relevância pois possibilitou a experiência em sala de aula e o entendimento sobre o contexto escolar e seus desdobramentos (Aluno SUP10).

[...] a extensão foi meu primeiro contato real com o universo da profissão que escolhi - a docência. Participar do projeto me fez entender as dificuldades enfrentadas diariamente pela gestão escolar para manter tudo funcionando, aprendi muito com os alunos e entendi o meu papel como futura docente (Aluna SUP06).

Corroborando com as narrativas acima, Freire (2011) afirma que conhecer é tarefa de sujeitos e o conhecimento é adquirido por meio de uma presença curiosa do sujeito em face do mundo, portanto, requer uma busca constante. As ações vivenciadas e compartilhadas entre os sujeitos possibilitarão o confronto das suas experiências e necessitarão de intervenções e interações de todos os envolvidos, proporcionando transformações sobre os problemas enfrentados. Para isso, é indispensável uma busca constante de suas demandas, a qual implica em inovação e em reinvenção de suas ações.

A participação em ações extensionistas impactou significativamente na formação acadêmica dos estudantes, oportunizando vivências e situações que não seriam possíveis somente em discussões teóricas da sala de aula, tornando-os mais críticos acerca da realidade e dos contextos locais, mais atuantes e participantes nos seus bairros e comunidades compreendendo sua função social como cidadãos, aplicando os conhecimentos adquiridos nos bancos escolares na prática.

\title{
Interdisciplinaridade e interprofissionalidade
}

A maioria dos respondentes, 93,3\%, considera que houve interdisciplinaridade e interprofissionalidade durante a realização das ações/projetos de extensão em que participaram, uma vez que aplicaram os conhecimentos teóricos adquiridos em sala de aula. 
Nas narrativas a seguir, têm-se alguns depoimentos de coordenadores e alunos quando perguntados sobre a interdisciplinaridade e interprofissionalidade na realização das suas ações de extensão:

É um complemento de ambas as partes entre o teórico e o prático, onde proporciona uma experiência com o público de forma diferente (Aluno SUBO3).

Eles conseguem ter uma dimensão da ação profissional e eu percebo assim a extensão, e é por isso que eu gosto tanto dos projetos de extensão em vários aspectos: é a comunidade enxergar o que é feito e receber um retorno de certa forma mais imediato. E o aluno poder perceber que a profissão dele não é somente aquilo que ele enxerga, mas perceber a amplitude de possibilidades de atuação dentro daquilo que ele tá fazendo e o terceiro divulgar os cursos que são feitos aqui, para que nós possamos ter mais alunos. Então essas três coisas que eu percebo como os carro chefe da extensão. (Coordenadora 03).

Participar de projetos de extensão me proporcionou contato direto com a minha área de estudo e futura profissão, permitindo-me desenvolver habilidades que apenas na teoria não seriam tão bem trabalhadas (Aluno SUP03).

Entende-se com Tardif (2002) que a prática da profissão docente exige outros saberes, para além daqueles aprendidos dentro do currículo do curso durante a formação. Experimentar situações que permitirão refletir, por exemplo, sobre o ensino e a aprendizagem, a utilização de abordagens pedagógicas diferenciadas, o diálogo com pessoas com pouca ou nenhuma escolaridade formal, dentre outras, é relevante para a formação inicial. Experiências, nesse sentido, são possíveis com a participação no desenvolvimento de ações extensionistas, porque elas possibilitam refletir sobre a prática da profissão docente.

Por ser de um curso de Licenciatura, os conhecimentos teóricos estudados nas disciplinas no curso se faziam presentes na prática do projeto de extensão o tempo todo, pois o professor precisa dominar uma série de saberes docentes, os quais, em maioria, se constituem a partir da prática do professor e o projeto de extensão proporciona situações nas quais estes saberes são postos em prática (Aluno SUP05).

Nesta mesma linha de pensamento, Tardif (2002) sugere ainda que os professores, desde sua formação inicial, precisam entrar em contato com situações concretas que demandam posicionamentos ou improvisações dificilmente desenvolvidas unicamente no ambiente da universidade. A seguir, têm-se algumas narrativas dos alunos sobre as experiências e desafios vivenciados nas ações de extensão:

O último projeto que realizei foi destinado aos conteúdos de geometria plana, porém ao chegar em uma das escolas nos deparamos com uma aluna com deficiência visual. Foi necessário utilizarmos técnicas estudadas em metodologia e práticas de ensino da matemática para adaptar o conteúdo e o material que trabalhamos (Aluno SUP11).

Ao fazer parte de atividades de extensão, os alunos percebem e já associam que os conhecimentos teóricos da sala de aula podem ser transformados em ação, e a partir do momento em que são socializados com as comunidades e Instituições podem influenciar e promover a transformação destes ambientes.

Outro fator perceptível é a 'internalização da profissão', em que o aluno começa a se reconhecer como profissional da área, percebe as dificuldades a serem enfrentadas, os desafios da profissão, o reconhecimento das diferentes possibilidades de atuação e potencializa as certezas ou incertezas pela escolha da profissão. 


\title{
Indissociabilidade ensino - pesquisa - extensão
}

A indissociabilidade ensino-pesquisa-extensão reafirma a extensão como processo acadêmico, em que, de acordo com o FORPROEX (2012), se coloca o estudante como protagonista de sua formação técnica - processo de obtenção de competências necessárias à atuação profissional - e de sua formação cidadã - processo que lhe permite reconhecerse como agente de garantia de direitos e deveres e de transformação social.

Neste sentido, Buarque (1994) é categórico ao afirmar que a extensão universitária tem se configurado, nos dias atuais, como um espaço de formação profissional e de ricas e qualitativas aprendizagens, onde os acadêmicos dispõem da possibilidade de compartilhar conhecimentos e vivências com docentes e discentes de diferentes áreas do saber, bem como experimentar a tomada de decisão, perceber-se como profissionais e desenvolver qualidades e habilidades relevantes para o desenvolvimento da prática profissional, compreendendo a mesma como práxis, ou seja, sem desvinculá-la da teoria social aprendida.

Conforme narrativa do coordenador a seguir, reafirma-se que a indissociabilidade entre ensino, pesquisa e extensão promove o aprimoramento de habilidades e competências aos alunos participantes, proporcionando-lhes uma formação diferenciada.

\section{Os alunos participantes dos projetos sempre tiveram um excelente aproveitamento acadêmico, conseguindo perpassar pelo ensino, pesquisa e extensão, tornando parte indissociável da sua formacão acadêmica, pois possibilitou aos mesmos novas vivências e uma melhor compreensão do mundo que os cerca. (Coordenador 2).}

Constata-se, a partir do relato abaixo, que a participação nos projetos de extensão para alunos do ensino médio integrado proporcionou aos participantes a oportunidade da iniciação científica, com submissão de resumos e participação em eventos. Essas experiências, a partir do ensino médio, melhor preparam os alunos, a partir do momento em que, ao ingressarem em cursos superiores de graduação, já estarão familiarizados com o universo da pesquisa, uma vez que já possuem esse contato prévio enquanto discentes da educação básica.

\begin{abstract}
Quando iniciei o ensino médio, jamais pensei que fosse fazer parte de algo tão importante quanto projetos de extensão. Atuar como bolsista na área do meio ambiente me auxiliou a desenvolver certa independência na tomada de decisões, me relacionar com pessoas desconhecidas em comunidades, abriu meus olhos para problemas sociais e ambientais tão próximos que podem ser combatidos graças às instituições de ensino locais. A oportunidade que é dada a determinados alunos para atuação como bolsista é algo que gera imensa gratidão, e fortalece ainda mais o vínculo com uma instituicão. $O$ desenvolvimento acadêmico cresce exponencialmente quando se iniciam as submissões e divulgações em eventos, como seminários, congressos, publicações em revistas, etc. São vivências que, sem dúvida, tornam os indivíduos íntegros, responsáveis e críticos, para que estes adentrem com diferenciais no mundo acadêmico elou profissional (Aluno EMIO3).
\end{abstract}

Foi muito importante para minha profissão e também para minha formação como pessoa. ão só pelos conhecimentos que adquiri (que não foram poucos), pude vivenciar diversas realidades e situações que quando formada estarei mais bem preparada. Essa troca de conhecimentos é muito rica, e, pela primeira vez fui incentivada a publicar em eventos e até participei de viagens para apresentação de trabalhos científicos (Aluno EMIO6).

Ao vivenciar essa nova realidade, Santana (1998) pontua que "o estudante forma conceitos próprios da realidade vivida, da maneira como se sentiu, dando significado aos dados recebidos como percepção, transformando-o em informação" e, com essas experiências, os estudantes tendem a aprender muito mais do que por meio de memorização de textos ou apenas o ensino na sala de aula.

É notável a percepção de que o conhecimento não se refere apenas aos saberes adquiridos ao exercício da sua própria área formativa, mas no entendimento de que sua ação provoca um benefício social. Outro fator relevante é o crescimento acadêmico a partir da descoberta da iniciação científica já na educação básica, onde os alunos têm acesso a conhecimentos adicionais, buscando resultados através de pesquisas, ampliando seus horizontes. 


\section{Impacto na formação do estudante}

De acordo com o Plano Nacional de Extensão, as atividades de extensão universitária constituem aportes decisivos à formação do estudante, seja pela ampliação do universo de referência que ensejam, seja pelo contato direto com as grandes questões contemporâneas que possibilitam. Esses resultados permitem o enriquecimento da experiência discente em termos teóricos e metodológicos, ao mesmo tempo em que abrem espaços para reafirmação e materialização dos compromissos éticos e solidários da universidade pública brasileira.

Como enfatiza Saraiva (2007, p. 228), a extensão universitária, juntamente com o ensino e a pesquisa, possibilitam a troca de saberes que podem resultar: "na produção de um conhecimento de novo tipo, resultante do confronto teoria e realidade, conhecimento científico e saber popular, que é concretizado na transformação cotidiana e permanente da sociedade".

Quando perguntados se avaliavam como positiva suas participações nos projetos de extensão, todos os sujeitos de pesquisa, foram unânimes (100\%) ao responderem que consideram como positiva tais vivências. $\mathrm{Na}$ narrativa a seguir, tem-se o relato da relevância dessas ações:

ormalmente, os alunos de licenciatura têm seu primeiro contato prático com a educação através do estágio supervisionado, no entanto, pude ter esse primeiro contato através de projetos de extensão. Deste modo, ao chegar no estágio já estava, de certa forma, mais familiarizada com o contexto escolar, com os alunos e com o planejamento das atividades (Aluno SUP16).

Com relação às características que os alunos consideram como mais relevantes para o desenvolvimento de ações de extensão, foram mais pontuadas as seguintes: comprometimento $(93,3 \%)$, trabalho em equipe $(90 \%)$, assiduidade $(83,3 \%)$, capacidade de tomada de decisão (80\%), e criatividade (76.7\%), conforme Gráfico 2.

Gráfico 2 - Características apontadas pelos alunos como mais relevantes para o desenvolvimento de ações de extensão.

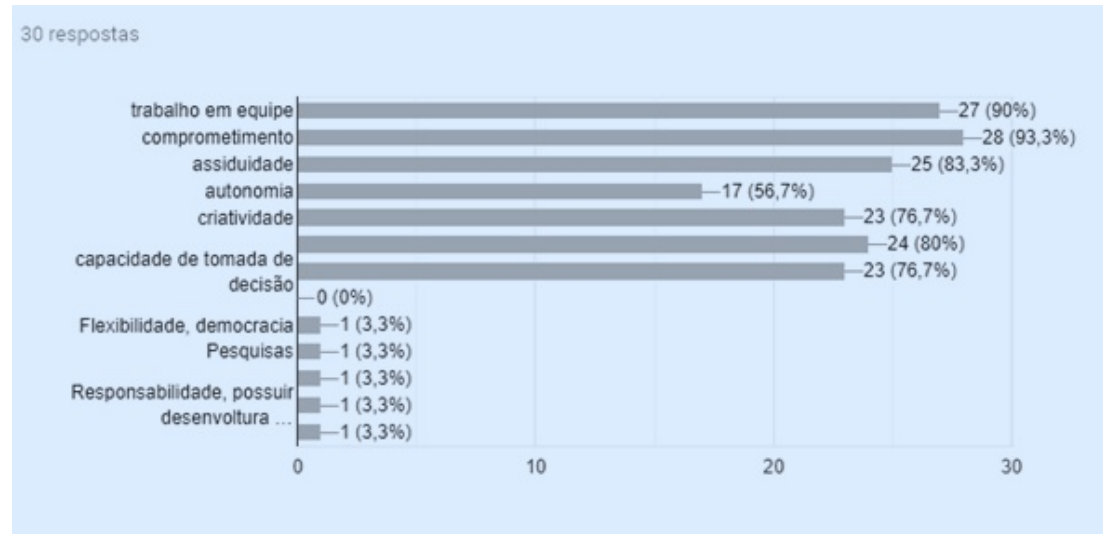

Fonte: Elaborado pela autora (2019).

Segundo Santos (2010), a extensão universitária deve ocupar um lugar: "tão importante quanto o ensino e a pesquisa, pois é, sobretudo, por meio dela que os dados empíricos imediatos e teóricos se confrontam, gerando as permanentes reelaborações que caracterizam a construção do conhecimento científico".

A seguir, tem-se a narrativa da Coordenadora 3, que reforça este entendimento:

Ainda ontem eu estava conversando com um aluno que é desse projeto de extensão que tá acontecendo esse ano e ele disse: "aaahh a hora que eu me vi ali, parece que eu saí de mim, e me vi explicando para os professores do curso de formacão continuada e me vi conduzindo a atividade e daí eu pensei bah que legal isso aqui, olha o que eu consigo fazer, parece que eu saí de mim e olhei de fora", lembro dessa nossa conversa! Então essa percepção, e, no caso da formação continuada, isso para os licenciandos, 
eles enxergam o quanto isso é importante. Além deles aprenderem com os professores e com o projeto coisas que eles não aprendem nas disciplinas porque cada coisa é uma vivência, cada situação é uma vivência, ainda tem a possibilidade de ver que, poxa esses professores estão atuando há um tempão e voltam para fazer o curso de extensão. Então quer dizer que realmente eu também não posso parar quando eu sair daqui. Aqui é só o início! (Coordenadora 3).

A narrativa evidencia o crescimento do aluno a partir da troca de vivências no decorrer do curso de formação, tendo em vista sentir-se mais seguro e confiante no domínio do conteúdo que seria aplicado. $O$ aluno percebe-se sujeito e também protagonista da sua própria trajetória acadêmica, à medida que compreende que suas escolhas e decisões irão repercutir no seu percurso formativo. Ter a iniciativa de conhecer o novo, de pesquisar novas temáticas, de argumentação e de desinibição é uma escolha, que quanto mais se pratica mais se aprimora.

As reflexões e práticas vivenciadas nas ações de extensão, de forma colaborativa, entre colegas e professores da rede pública, permitem encontrar novas possibilidades e novos caminhos, ampliar, aprofundar e ressignificar os estudos teóricos e metodológicos do contexto escolar, repercutindo nas trajetórias acadêmicas e profissionais de cada estudante.

$\mathrm{Na}$ narrativa a seguir, tem-se o relato de uma aluna egressa do campus que participou de ações de extensão durante os três anos em que cursou o ensino médio integrado:

\begin{abstract}
Participei como bolsista do projeto de extensão Café com Livros durante três anos, dos 13 aos 16 anos. Portanto, tive contato com grandes responsabilidades desde cedo, o que auxiliou muito na constituição da pessoa que sou hoje, participei de vários eventos e publiquei alguns trabalhos. Resultado: com 16 anos entrei na faculdade de Letras-Português na UFSM, já consegui bolsa aqui devido ao currículo Lattes que formei enquanto estava no ensino médio, sendo bolsista do projeto de extensão. Além de atualmente possuir um currículo bom para alguém da minha idade, 17 anos, tenho marcado características pessoais que foram desenvolvidas durante e com o auxílio do projeto (Aluna SMA 04).
\end{abstract}

Conforme se percebe no relato, é de extrema importância que os alunos do ensino médio tenham um contato inicial com a realização de projetos (seja de pesquisa ou de extensão), bem como vivenciem possibilidades de participação em eventos e seminários e experimentem a iniciação científica. Estes fatores impactam positivamente na formação dos alunos em médio e longo prazo, uma vez que eles apresentam um bom desempenho acadêmico, estando mais preparados e qualificados para o ingresso no ensino superior e com um currículo diferenciado, aproximando-os do mundo universitário. Também levam consigo saberes, habilidades, vivências e concepções cidadãs que vão além do conhecimento científico e que compõem sua formação.

\title{
Impacto e transformação social
}

O FORPROEX reafirma a atuação transformadora da Extensão Universitária e indica que ela deve ser desenvolvida com vistas a ser: "voltada para os interesses e necessidades da maioria da população e propiciadora do desenvolvimento social e regional, assim como para o aprimoramento das políticas públicas" (FÓRUM, 2012, p. 35).

Como se pode observar nas narrativas a seguir, os alunos têm consciência da importância das ações de extensão desenvolvidas e percebem o impacto que elas causam nas comunidades locais:

os projetos em que nos deslocamos até as escolas foi muito importante a vivência com a sociedade escolar local. Todas eram em escolas de periferia $e$ de vulnerabilidade social então a vivência com a realidade me fez entender 
o todo. Por outro lado, os projetos de formação continuada foram essenciais para a percepção em relação a visão do professor, o que me espera após o término da graduação e o quanto aquela ação que estávamos fazendo era importante, pois este é o único momento de formação de professores que eles recebem no ano (Aluno SUP02).

$O$ projeto de extensão - Produção de sabão: geração de renda e sustentabilidade nos aproximou da sociedade pois estávamos transmitindo conhecimento à outras famílias, fazendo com que elas aprendessem a fazer o sabão e também a partir daí tivessem a possibilidade de conseguir uma renda extra mudando sua situação. $O$ curso foi ministrado nas associações de bairro da cidade e nos CRAS, e teve a participação de mais de 100 pessoas (Aluno EMIO5).

Por meio dos projetos de extensão a nossa visão e relação com a sociedade muda completamente, porque é através da interação entre a nossa instituição e a comunidade que percebemos que tendo envolvimento, vontade, comprometimento e incentivo, podemos contribuir de forma significativa na vida das pessoas, no desenvolvimento da nossa cidade, na valorização da educação e no crescimento e visibilidade da nossa instituição de ensino (Aluno SUP04).

O impacto e a transformação social podem ocorrer diretamente ou indiretamente. Algumas ações de extensão são desenvolvidas e imediatamente oportunizam contribuições relevantes para a transformação das comunidades atendidas, qualificando e capacitando os envolvidos. Outras ações de extensão são desenvolvidas e impulsionam a formação de alunos e de professores de escolas públicas municipais e estaduais, através de projetos de monitoria, reforço escolar, incentivo à leitura, educação ambiental, formação continuada de professores, refletindo na qualidade do processo formativo dos educandos a longo prazo.

Neste sentido, constatou-se que os estudantes participantes de ações de extensão adquiriram crescimento profissional, desenvolvimento humano e pessoal, bem como concepções cidadãs, conforme se verifica no Quadro 3, a seguir.

Quadro 3 - Contribuições adquiridas pelos estudantes participantes de ações de extensão.

\begin{tabular}{|c|c|c|}
\hline $\begin{array}{l}\text { Crescimento } \\
\text { profissional }\end{array}$ & $\begin{array}{l}\text { Desenvolvimento } \\
\text { humano e pessoal }\end{array}$ & Concepções cidadãs \\
\hline $\begin{array}{l}\text { - Construção e } \\
\text { ressignificação de } \\
\text { saberes } \\
\text { - Aplicação prática dos } \\
\text { conceitos teóricos } \\
\text { adquiridos em sala de } \\
\text { aula } \\
\text { - Internalização da } \\
\text { profissão } \\
\text { - Aprimoramento de } \\
\text { habilidades } \\
\text { - Aumento da produção } \\
\text { científica } \\
\text { - Participação em eventos } \\
\text { Socialização de } \\
\text { conhecimentos }\end{array}$ & $\begin{array}{l}\text { - Habilidade de trabalhar } \\
\text { em equipe } \\
\text { - Interação com } \\
\text { diferentes grupos sociais } \\
\text { - Respeito pelo outro e } \\
\text { pelas trajetórias de vida } \\
\text { de cada um; } \\
\text { - Troca de } \\
\text { vivências/experiências } \\
\text { - Solidariedade } \\
\text { Responsabilidade e } \\
\text { ética. }\end{array}$ & $\begin{array}{l}\text { Desenvolvimento da } \\
\text { criticidade } \\
\text { - Sujeitos ativos na } \\
\text { sociedade } \\
\text { comprometidos com a } \\
\text { transformação social } \\
\text { Superação das inúmeras } \\
\text { desigualdades sociais. }\end{array}$ \\
\hline
\end{tabular}

Fonte: Elaborado pela autora (2019). 


\section{Considerações finais}

A pesquisa confirmou que a extensão é extremamente relevante para a formação acadêmica e profissional dos estudantes, uma demanda cada vez mais emergente e necessária na instituição, bem como na sociedade. O IFFar, como instituição pública e de qualidade, necessita manter o seu investimento interno nas ações de extensão, considerando o cumprimento do seu papel social de promover o desenvolvimento local e regional, além do processo de formação acadêmica, profissional e cidadã dos estudantes.

Em relação à contribuição destas ações para o processo formativo dos alunos, constatou-se que houve aprimoramentos de habilidades, crescimento pessoal e profissional, incorporação de novas práticas e conhecimentos, aumento da produção científica, participação em eventos e socialização de conhecimentos.

Tal vivência concreta resultou em experiências profissionais que geraram construção e ressignificação de saberes, evidenciando a aplicação prática dos conceitos teóricos aprendidos em sala de aula, reconhecendo-se como futuros profissionais.

No desenvolvimento humano e pessoal, verificou-se a habilidade de trabalhar em equipe, interação com diferentes grupos sociais, respeito pelo outro, troca de experiências, solidariedade, a importância da responsabilidade e da ética. Ainda, verificou-se que os participantes adquiriram concepções cidadãs, haja vista que desenvolveram e/ou aprimoraram a criticidade, tornando-se sujeitos ativos na sociedade, comprometidos com a transformação social e superação das inúmeras desigualdades sociais existentes. Neste sentido, as ações de extensão proporcionam uma formação diferenciada, fortalecendo o protagonismo estudantil e contribuindo na formação acadêmica, profissional, pessoal e cidadã dos envolvidos.

A publicação de uma Política Nacional de Extensão universitária foi um grande marco para a valorização da extensão, pois propiciou que cada instituição elaborasse suas próprias políticas de extensão, definindo os seus próprios caminhos, considerando sua missão Institucional e propondo estratégias para consolidação de suas ações extensionistas. Outro ponto relevante está relacionado à institucionalização da extensão, visto que a maioria das Instituições de ensino superior já possuem esta estrutura organizada com Pró-Reitorias e demais setores vinculados.

No entanto, os irrisórios investimentos externos de agências financiadoras em ações de extensão reflete-se no interesse, por parte dos estudantes, em muitas vezes optar pela realização de projetos de pesquisa, uma vez que contam com maior investimento, maior oferta de bolsas, status na iniciação científica e pontuações melhores em seleções públicas (mestrado, doutorado).

A Política Nacional de Extensão da Rede Federal de Educação Profissional e Tecnológica é ainda muito recente (2012), de modo que ainda há desafios a serem enfrentados para sua efetiva consolidação. Faz-se necessário a conquista por mais espaços para a desconstrução da hegemônica hierarquia entre o ensino-pesquisa-extensão, uma vez que, em termos de formação, os saberes se misturam e se autorrelacionam.

\section{Referências}

BRASIL. Assembleia Nacional Constituinte. Constituição da República Federativa do Brasil. Atualizada até a Emenda Constitucional n.38, de 12/06/2002. Brasília: Diário Oficial da União, de 05/10/1988.

BRASIL. Lei de criação da Rede Federal de Educação Profissional, Cientifica e

Tecnológica. Lei 11.892 de 29 de dezembro de 2008. Brasília: Diário Oficial da União, 2008. 
BARDIN, L. Análise de conteúdo. Lisboa: Edições 70, 2009.

BUARQUE, C. A aventura da universidade. São Paulo: Editora da UNESP; Rio de Janeiro: Paz e Terra, 1994.

FREIRE, P. Extensão ou Comunicação? São Paulo: Paz e Terra, 2011.

FORPROEX. Fórum de Pró-Reitores de Extensão das Universidades Públicas

Brasileira: organização e sistematização; organização: Edison José Corrêa. Coordenação Nacional do FORPROEX. Belo Horizonte: Coopmed, 2007. Disponível América Latina. Buenos Aires: Editorial Miño y Dávila, 2012.

GIL, A. C. Métodos e técnicas de pesquisa social. 6. ed. São Paulo: Atlas, 2012.

LARROSA, Jorge Bondía. Notas sobre a experiência e o saber da experiência. Revista Brasileira de Educação, n 19, 2002.

PEREIRA, L. A. C. Institutos Federais de Educação, Ciência e Tecnologia. Brasília: Ministério da Educação, 2009. Disponível em:

$<$ http://portal.mec.gov.br/setec/arquivos/pdf3/artigos_ifet_jornal.pdf $>$ Acesso em: 12 nov. 2017.

SANTOS, M. P. Contributos da Extensão Universitária brasileira à formação acadêmica docente e discente no século XXI: um debate necessário. Revista Conexão UEPG, v.6, n.1, p.10-15, 2010. Disponível em: http://

www.uepg.br/revistaconexao/revista/edicao06/1.pdf Acesso em: 17.abr. 2019.

SANTANA, M. J. A. UFBA em Campo. 1996 -1998: uma experiência de articulação ensino, pesquisa e sociedade. Salvador: UFBA, 1998.

SARAIVA, J. L. Papel da extensão universitária na formação de estudantes e professores. Brasília Med., v. 44, n. 3, p. 225-233, 2007.

SEVERINO, Antônio Joaquim. Metodologia do trabalho científico. São Paulo: Cortez, 2007.

SILVA, O. da. O que é extensão universitária. Integração: ensino, pesquisa e extensão, São Paulo, v. 3, n. 9, p. 148-149, maio 1997.

SÍVERES. A Extensão universitária como um princípio de aprendizagem. Brasília: Liber Livro, 2013.

SCHEIDEMANTEL, S. E. et al. A Importância da Extensão Universitária: o Projeto Construir. In: Congresso Brasileiro de Extensão Universitária, II., 2004, Belo Horizonte. Anais... Belo Horizonte, 2004, p. 1-6.

SOUSA, Ana Luiza Lima. A história da extensão universitária. Campinas: Alínea, 2000 .

TARDIF, M. Saberes docentes e formação profissional. Petrópolis: Vozes, 2002. 